\title{
Do First Year College Female and Male Students Hold Different Misconceptions about Force and Motion?
}

\author{
H. N. Bani-Salameh ${ }^{1}$, M. Nuseirat ${ }^{1}$, K. A. Alkofahi ${ }^{2}$ \\ ${ }^{1}$ Department of Basic Sciences, College of Science and Health Professions, King Saud Bin Abdulaziz University \\ for Health sciences, Ministry of National Guard Health Affairs, Mail Code (3124), PO Box 3660, Riyadh 11481, \\ Kingdom of Saudi Arabia. \\ ${ }^{2}$ Department of Economics, Princess Nourah Bit Abdulrahman University, College of Business and \\ Administration, postal code 11671, P.O. box 84428, Riyadh, Kingdom of Saudi Arabia.
}

\begin{abstract}
Our main purpose of the current research project is to improve the whole physics educational process at our university, not only the learning side from our students but also the teaching side from us instructors. In this report we discuss the part of the big project dedicated to the study of common dominant misconceptions among male and female students about force and motion. We used the force concept inventory (FCI) as a study tool for this work and was given to our students as a pre and post test. Although our previous study showed an outperformance of our male students over females in almost all items from the inventory, this study shows that both groups are still holding the same kind of misconceptions. We were able to find a full list of common misconceptions between the two groups using the method of dominant incorrect answers.
\end{abstract}

Keywords: Force concept Inventory. Force and motion in physics. Common misconceptions. Dominant incorrect answers. Physics education research.

\section{Introduction}

We started this part of our project with the goal of detecting any common misconceptions among male and female students. In a previous publication [1], we reported a gender gap in performance in favor of male students and were immediately interested in studying the kind of misconceptions held by both groups and if they're related. We gave the force concept inventory (FCI) [2] to both groups once at the beginning of the semester before they receive any instructions on force and motion (pre-test) and once after (post-test). Six different sections participated in this study with a final count of 341 students (177 females and 164 males). The reason for considering the results of both tests for this study is to check if any detected common misconceptions will persist after instructions. To analyze the results of the FCI test, we used a method first suggested by MartínBlas et al., (2010) [3] where we study all incorrect answers to all questions in the inventory. Every incorrect answer in the inventory is probing a certain misconception, therefore; by studying students' answers in all tests, we were able to identify a full list of common dominant misconceptions between the two groups. Details about this method and the analysis used can be found below in section 3 along with dedicated sections for data collection (section 2) and results and discussions (section 4) and we finish with some concluding remarks in section 5 .

\section{Data Collection}

The revised version of the Force Concept Inventory (FCI) [2] was used in this study containing 30 conceptual questions about force and motion. One of the purposes of giving the FCI is to detect different misconceptions held by students [4-9]. All questions have five possible answers; one correct and four distracters. If you're just studying student's performance, you would be interested in the number of correct answers for each student, but if you're after misconceptions then you should pay more attention to incorrect answers. Each wrong answer is carefully written to test for certain misconception based on students' answers and one-on-one interviews with them afterward. The authors of the original paper included a taxonomy of misconceptions which was used to determine common dominant misconceptions among the two groups under study in both tests.

Table 1. A taxonomy of Naïve conceptions probed by the Force Concept Inventory (Adapted from Hestenes et al.1992 and Bani-Salameh 2016b).

\begin{tabular}{|l|l|l|}
\hline Code & Misconception & Inventory item \\
\hline Kinematics & Position- velocity undiscriminated & $19 \mathrm{~B}, \mathrm{C}, \mathrm{D}$ \\
\hline K1 & Velocity- acceleration undiscriminated & $19 \mathrm{~A} ; 20 \mathrm{~B}, \mathrm{C}$ \\
\hline K2 & Nonvectorial velocity composition & 9C \\
\hline K3 & Ego- centered reference frame & $14 \mathrm{~A}, \mathrm{~B}$ \\
\hline K4 &
\end{tabular}


Do First Year College Female and Male Students Hold Different Misconceptions About Force and

\begin{tabular}{|c|c|c|}
\hline \multicolumn{3}{|c|}{ Impetus } \\
\hline I1 & Impetus supplied by "hit" & 5C,D,E; 11B,C; 27D; 30B,D,E \\
\hline I2 & Loss/recovery of original impetus & 7D;8C,E; 21A; 23A,D \\
\hline I3 & Impetus dissipation & 12C,D; 13A,B,C; 14E; 23D; 24C,E;27B \\
\hline I4 & Gradual/delayed impetus build- up & $8 \mathrm{D} ; 10 \mathrm{~B}, \mathrm{D} ; 21 \mathrm{D} ; 23 \mathrm{E} ; 26 \mathrm{C} ; 27 \mathrm{E}$ \\
\hline I5 & Circular impetus & 5C,D,E; 6A; 7A,D; 18C,D \\
\hline \multicolumn{3}{|c|}{ Active forces } \\
\hline AF1 & Only active agents exert forces & 15D;16D; 17E; 18A; 28B; 30A \\
\hline AF2 & Motion implies active force & 5C,D,E;27A \\
\hline AF3 & No motion implies no force & $29 \mathrm{E}$ \\
\hline AF4 & Velocity proportional to applied force & $22 \mathrm{~A} ; 26 \mathrm{~A}$ \\
\hline AF5 & Acceleration implies increasing force & $3 \mathrm{~B}$ \\
\hline AF6 & Force causes acceleration to terminal velocity & $3 \mathrm{~A} ; 22 \mathrm{D} ; 26 \mathrm{D}$ \\
\hline AF7 & Active force wears out & $22 \mathrm{C}, \mathrm{E}$ \\
\hline \multicolumn{3}{|c|}{ Action-Reaction pairs } \\
\hline AR1 & Greater mass implies greater force & 4A,D; 15B; 16B; 28D \\
\hline AR2 & Most active agent produces greatest force & $15 \mathrm{C} ; 16 \mathrm{C} ; 28 \mathrm{D}$ \\
\hline \multicolumn{3}{|c|}{ Concatenation of influence } \\
\hline CI1 & Largest force determines motion & 17A,D; $25 \mathrm{E}$ \\
\hline CI2 & Force compromise determines motion & $6 \mathrm{D} ; 7 \mathrm{C} ; 12 \mathrm{~A} ; 14 \mathrm{C} ; 21 \mathrm{C}$ \\
\hline CI3 & Last force to act determines motion & $8 \mathrm{~A} ; 9 \mathrm{~B} ; 21 \mathrm{~B} ; 23 \mathrm{C}$ \\
\hline \multicolumn{3}{|c|}{ Other influences on motion } \\
\hline CF & Centrifugal force & 5E; 6C,D,E; 7C,D,E;18E \\
\hline $\mathbf{O b}$ & Obstacles exert no force & 4C; $5 \mathrm{~A} ; 11 \mathrm{~A}, \mathrm{~B} ; 15 \mathrm{E} ; 16 \mathrm{E} ; 18 \mathrm{~A} ; 29 \mathrm{~A}$ \\
\hline \multicolumn{3}{|c|}{ Resistance } \\
\hline R1 & Mass makes things stop & $27 \mathrm{~A}, \mathrm{~B}$ \\
\hline $\mathbf{R 2}$ & Motion when force overcomes resistance & $25 \mathrm{~A}, \mathrm{~B}, \mathrm{D} ; 26 \mathrm{~B}$ \\
\hline $\mathbf{R 3}$ & Resistance opposes force/impetus & $26 \mathrm{~B}$ \\
\hline \multicolumn{3}{|c|}{ Gravity } \\
\hline G1 & Air pressure- assisted gravity & 3E; 11A; 17D; 29C; 29D \\
\hline G2 & Gravity intrinsic to mass & 3D; 11E; 13E; 29C \\
\hline G3 & Heavier objects fall faster & $1 \mathrm{~A} ; 2 \mathrm{~B}, \mathrm{D}$ \\
\hline G4 & Gravity increases as objects fall & 3B;13B \\
\hline G5 & Gravity acts after impetus wears down & 12D; 13B; 14E \\
\hline
\end{tabular}

In an earlier published paper [4], we included two tables as a reconstruction of the taxonomy of misconceptions that appeared for the first time in Hestenes et al., (1992) [2]. The reason for this reconstruction was to find misconceptions associated with a certain choice of each question faster. One of the two tables included codes representing different misconceptions and the other one showed all misconceptions arranged by question number and the five possible answers of each question. In this paper we include only one table (Table 1) adapted from the original paper and from our other paper [5]. This table will serve as our reference to different codes associated with different misconceptions.

From Table 1 one can identify misconceptions associated with students' answers to any question in the inventory. If a student chose answer $\boldsymbol{A}$ for question number 29 for example, we can see it's the code $\mathbf{O B}$ associated with this answer and that means the student has the misconception of "Obstacles exert no force". In the case they choose answer $\boldsymbol{C}$ for this question, there are two codes showing under that choice; G1 and G2. Whenever there exists more than one code under the same answer that means this answer might have been driven by more than one misconception that the student have. In this particular case, the two misconceptions are related to gravity.We used the dominant incorrect answer method [3] to analyze the data collected. This method helped in the detection of common dominant misconceptions between the two groups. For any misconception to be considered dominant, certain incorrect answer/s for a certain question must be chosen by students $50 \%$ more times than other incorrect answers for that particular question, more on the details of this method is discussed in section 3 .

\section{Data Analysis}

Before we start our discussion on common misconceptions found among our male and female students, we should mention first that we already have reported on weak overall performance of both groups with male students outperforming females in almost all items from the inventory [1]. With that being said, now we turn our attention to our goal from this study to identify common misconceptions. We used the analysis of the dominant incorrect answers [3] where we examined all incorrect answers of every question in the pre and post FCI tests for males and females with results reported in Table 2. All dominant misconceptions found from students' incorrect answers are listed in column 1 as codes (see Table 1). Column 2 lists the item number from the FCI test where the misconceptions where found. The last four columns list the percentages of the incorrect answer/s in pre and post tests for both males and females. Some of these numbers are less than the $50 \%$ threshold but were listed for comparison. 
To get any useful information from Table 2 it should be noted that these numbers in the last four columns do not represent percentages of students answering a single incorrect answer only nor is normalized to the total number of students. To identify common misconceptions, we followed information given in table 1 where there might be more than one choice in a single question driven by the same misconception. Therefore; to find the percentage of that misconception, we had to add these incorrect answers together and then divide the result by the number of incorrect answers for that question. If the percentage is more than $50 \%$, that misconception is considered to be dominant for any question $[5,5]$.

\section{Results And Discussion}

To study Table 2 in details, we take one of the items listed and whatever applies to it can be extended to the rest of the items. In Table 2 we find the code AF2 which according to table 1 is the misconception of "Motion implies active force". This misconception was detected from students' answers to be dominant in two questions; 5 and 27 for all tests given for both males and females. Numbers associated with these two questions in Table 2 represent percentages of students picking certain wrong answer/s. In the case of question 5, there are three different incorrect answers driven by the misconception AF2, namely $\boldsymbol{C}, \boldsymbol{D}$ and $\boldsymbol{E}$ (see Table 1). Based on this, the first number being $86 \%$ means there were $86 \%$ of the total number of male students not answering $\mathbf{Q 5}$ correctly in the pre test chose one of these three wrong answers. The second column is for female students in the pre-test, the third column is for male students in the post-test and the last column is for female students in the post-test. For $\mathbf{Q 2 7}$, it's only one choice driven by the misconception AF2 (choice $\boldsymbol{A}$ ) and the numbers in this case represent the percentages of students choosing a single wrong answer.

Table 2. Dominant misconceptions' codes (see Table 1) with corresponding inventory item and the normalized number of incorrect answers (\%) for both male and female students in pre and post tests.

\begin{tabular}{|c|c|c|c|c|c|}
\hline $\begin{array}{l}\text { Misconception } \\
\text { Code }\end{array}$ & $\begin{array}{l}\text { Question } \\
\text { Number }\end{array}$ & $\begin{array}{l}\text { Pre } \\
\mathrm{M}\end{array}$ & $\begin{array}{l}\text { Pre } \\
\text { F } \\
\end{array}$ & $\begin{array}{l}\text { Post } \\
\mathrm{M} \\
\end{array}$ & $\begin{array}{l}\text { Post } \\
\text { F }\end{array}$ \\
\hline \multirow[t]{2}{*}{$\mathrm{K} 1$} & 19 & $71 \%$ & $63 \%$ & $65 \%$ & $80 \%$ \\
\hline & 20 & $67 \%$ & $49 \%$ & $77 \%$ & $63 \%$ \\
\hline K3 & 9 & $60 \%$ & $40 \%$ & $67 \%$ & $36 \%$ \\
\hline K4 & 14 & $96 \%$ & $86 \%$ & $80 \%$ & $89 \%$ \\
\hline \multirow[t]{3}{*}{ I1 } & 5 & $86 \%$ & $85 \%$ & $99 \%$ & $95 \%$ \\
\hline & 11 & $65 \%$ & $78 \%$ & $84 \%$ & $83 \%$ \\
\hline & 30 & $97 \%$ & $95 \%$ & $94 \%$ & $98 \%$ \\
\hline \multirow[t]{4}{*}{ I3 } & 12 & $95 \%$ & $75 \%$ & $95 \%$ & $84 \%$ \\
\hline & 13 & $97 \%$ & $96 \%$ & $99 \%$ & $99 \%$ \\
\hline & 23 & $80 \%$ & $58 \%$ & $75 \%$ & $69 \%$ \\
\hline & 24 & $75 \%$ & $80 \%$ & $67 \%$ & $71 \%$ \\
\hline I4 & 10 & $79 \%$ & $45 \%$ & $80 \%$ & $59 \%$ \\
\hline \multirow[t]{4}{*}{ I5 } & 5 & $86 \%$ & $85 \%$ & $99 \%$ & $95 \%$ \\
\hline & 6 & $79 \%$ & $54 \%$ & $45 \%$ & $58 \%$ \\
\hline & 7 & $51 \%$ & $66 \%$ & $21 \%$ & $70 \%$ \\
\hline & 18 & $61 \%$ & $64 \%$ & $60 \%$ & $63 \%$ \\
\hline \multirow[t]{2}{*}{$\mathrm{AF} 2$} & 5 & $86 \%$ & $85 \%$ & $99 \%$ & $95 \%$ \\
\hline & 27 & $68 \%$ & $56 \%$ & $60 \%$ & $58 \%$ \\
\hline AF5 & 3 & $59 \%$ & $33 \%$ & $45 \%$ & $55 \%$ \\
\hline AF6 & 22 & $49 \%$ & $51 \%$ & $64 \%$ & $50 \%$ \\
\hline \multirow[t]{2}{*}{ AR1 } & 4 & $77 \%$ & $69 \%$ & $77 \%$ & $64 \%$ \\
\hline & 28 & $56 \%$ & $55 \%$ & $81 \%$ & $37 \%$ \\
\hline \multirow[t]{3}{*}{ AR2 } & 15 & $45 \%$ & $32 \%$ & $80 \%$ & $49 \%$ \\
\hline & 16 & $52 \%$ & $24 \%$ & $68 \%$ & $48 \%$ \\
\hline & 28 & $56 \%$ & $55 \%$ & $81 \%$ & $37 \%$ \\
\hline \multirow[t]{2}{*}{ CI1 } & 17 & $89 \%$ & $78 \%$ & $95 \%$ & $89 \%$ \\
\hline & 21 & $42 \%$ & $25 \%$ & $57 \%$ & $28 \%$ \\
\hline $\mathrm{CI} 3$ & 8 & $60 \%$ & $63 \%$ & $58 \%$ & $68 \%$ \\
\hline \multirow[t]{2}{*}{$\mathrm{CF}$} & 6 & $21 \%$ & $46 \%$ & $55 \%$ & $42 \%$ \\
\hline & 7 & $55 \%$ & $52 \%$ & $83 \%$ & $41 \%$ \\
\hline \multirow[t]{2}{*}{$\mathrm{Ob}$} & 11 & $69 \%$ & $44 \%$ & $42 \%$ & $34 \%$ \\
\hline & 29 & $77 \%$ & $58 \%$ & $25 \%$ & $34 \%$ \\
\hline R1 & 27 & $92 \%$ & $89 \%$ & $94 \%$ & $89 \%$ \\
\hline R2 & 25 & $83 \%$ & $67 \%$ & $85 \%$ & $95 \%$ \\
\hline G1 & 29 & $17 \%$ & $33 \%$ & $67 \%$ & $54 \%$ \\
\hline \multirow[t]{2}{*}{ G3 } & 1 & $59 \%$ & $37 \%$ & $53 \%$ & $25 \%$ \\
\hline & 2 & $47 \%$ & $49 \%$ & $52 \%$ & $40 \%$ \\
\hline \multirow[t]{2}{*}{ G4 } & 3 & $59 \%$ & $33 \%$ & $45 \%$ & $55 \%$ \\
\hline & 13 & $52 \%$ & $32 \%$ & $43 \%$ & $26 \%$ \\
\hline G5 & 13 & $52 \%$ & $32 \%$ & $43 \%$ & $26 \%$ \\
\hline
\end{tabular}


Table 2 offers a lot of information about misconceptions held by our students but we'll focus our discussion on few interesting cases. All misconceptions listed in table 2 seemed to be common dominant misconceptions by males and females except for: I4, AR2, CF, G4 and G5. We made this conclusion based on the fact that there are different percentages for males and females associated with these particular misconceptions (see Table 2). Many of these common misconceptions showed high persistent even after instructions where we see high percentages of male and female students in both the pre and the post tests having these misconceptions. One example is the misconception of the "Impetus dissipation I3"; this misconception is probed by six different questions in the inventory and was found to be dominant in four of them: $Q 12, Q 13, Q 23$ and $\mathbf{Q 2 4}$. It's not only being dominant in these questions but also with almost the same percentages in both tests for both groups. This is a clear indication of common way of thinking among all students; males and females.

Other interesting cases we found in Table 2 are related to some misconceptions being common in some questions probing it and not others. One example is the misconception of "Largest force determines motion CI1" where it's probed in $Q 17$ and $Q 21$; it was found to be common among males and females with very similar percentages in $\boldsymbol{Q 1 7}$ but not in $\mathbf{Q 2 1}$, it's not only not common but not even dominant in $\boldsymbol{Q 2 1}$. One indication of this might be in the way these two questions are formatted, students were able to understand and answer $\mathbf{Q 2 1}$ better than $\mathbf{Q 1 7}$. Or the possibility that students have more than one misconception and there were no clear winner in $Q 21$.

There are cases in Table 2 were we detected common dominant misconceptions for males and females in the pre test and it wasn't even dominant in the post test (example is the misconception of "Obstacles exerts no force" $\mathbf{O b}$ ). We also detected the reverse effect were a certain misconception is not common in the pre test but it is in the post test (the misconception of "Air pressure-assisted gravity" G1). These two mentioned misconceptions are both probed in different answer choices in question 29 and what we detected was most likely due to students holding the two misconceptions at the same time and just guessing the answer in this case.The last comment we want to make regarding Table 2 is it's relation to the gender difference. We showed a clear evidence in a previous work [1] of a gender gap in the students' performance measured by the FCI, here we also show evidence of common misconceptions between them. This is telling us that these misconceptions are universal and don't depend on gender; even though our male students outperformed our female students in almost all the inventory items, both still hold the same misconceptions. One example from table 2 that show this point clearly is the misconception of "Motion implies active force AF2" which is probed in Q5 and Q27. As was shown in our previous report [1], females slightly outperformed males in Q5 but were outperformed by males in Q27 but nevertheless all of them had this common dominant misconception in all tests.

\section{Conclusions}

We dedicated this study to identify any common misconceptions among our students. We used the FCI as our measurement instrument and gave it to our students before and after they received instructions on force and motion. We used the method of dominant incorrect answers to identify common misconceptions. Even though male and female students scored differently on the FCI tests [1], results of this study showed clear evidence that they all hold same misconceptions. Similar results were reported before regarding the universal nature of Newtonian mechanics misconceptions [10-13]. This report serves as one of the first few steps in our main project; we aim at a whole evaluation and then reconstruction of our physics education process at our school. We started by the evaluation part (this report and previous ones [1, 2-3, 14]) and the next stage of reconstruction will follow. The next stage will require some careful planning to redesign our instructions and the way they're delivered to students. This change must be based on our results and the results from other researchers all around the world. After that we have to run tests again to see if we managed to make any difference in students' performance in the post test or if we were able to reduce (or even hopefully eliminate) gender gap in performance.

References

[1]. Bani-salameh H.N., Nuseirat M., Alkofahi K.A., Performance gap among male and female college students measure with the force concept inventory, (submitted to IOSR for publication).

[2]. Hestenes, D., Wells, M. \& Swackhamer, G. (1992). Force concept inventory. The Physics Teacher, 30 (3), 141-158

[3]. Martín-Blas Teresa, Seidel Luis \& Serrano-Fernández Ana (2010). Enhancing Force Concept Inventory diagnostics to identify dominant misconceptions in first-year engineering physics. European Journal of Engineering Education 35 (6), 597-606

[4]. Bani-Salameh H.N. (2017). Using the Method of Dominant Incorrect Answers with the FCI Test to Diagnose Misconceptions Held by First Year College Students. Phys. Educ. 52015006

[5]. Bani-Salameh H.N. (2017). How persistent are the misconceptions about force and motion held by College Students. Phys. Educ. 52014003

[6]. Halloun I and Hestenes D 1995 Interpreting the Force Concept Inventory Phys. Teach. 33 502-6

[7]. Savinainen, A. and Scott, P., (2002a). The Force Concept Inventory: a tool for monitoring student learning. Physics Education, 37 (1), 45-52.

[8]. Savinainen, A. and Scott, P., (2002b). Using the Force Concept Inventory to monitor student learning and to plan teaching. Physics Education 37 (1), 53-58. 
[9]. Savinainen, A. and Viri, J., (2008). The Force Concept Inventory as a measure of students'conceptual coherence.International Journal of Science and Mathematics Education, 6 (4), 719-740.

[10]. Viiri, J. (1996). Teaching the force concept: a constructivist teaching experiment in engineering education. European Journal of Engineering Education, 21 (1), 55-63.

[11]. Bogdanov S and Viiri J 1999 Students' understanding of the force concept in Russia and Finland Proc. Of the $2^{\text {nd }}$ Int. Conf. of the European Science Education Research Association (ESERA) ed M Komorek et al (Kiel,August 1999)

[12]. Cayhadi, V. (2004). The effect of interactive engagement teaching on student understanding of introductory physics at the faculty of engineering, University of SurabayaIndonesia. Higher Education Research \& Development, 23 (4), 455-464

[13]. Sule Bayraktar, (2009), Misconceptions of turkish pre-service teachers about force and motion,International Journal of Science and Mathematics Education, 7 (2), 273-291

[14]. Bani-Salameh H.N. (2017). Teaching language effects on students' performance. Health Professions Education, (2017) (in press), http: //dx.doi.org/10.1016/j.hpe.2017.01.005. 